\title{
Response and Adherence to Nilotinib in Daily practice (RAND study): an in-depth observational study of chronic myeloid leukemia patients treated with nilotinib
}

\author{
Christel C. L. M. Boons ${ }^{1,2}$ (D) - Lonneke Timmers ${ }^{1,2} \cdot$ Jeroen J. W. M. Janssen $^{3} \cdot$ Peter E. Westerweel $^{4}$. $^{2}$ \\ Nicole M. A. Blijlevens ${ }^{5}$ • Willem M. Smit ${ }^{6}$ • Imke H. Bartelink ${ }^{1}$ • Janneke A. Wilschut ${ }^{2}$ • Eleonora L. Swart ${ }^{1}$. \\ N. Harry Hendrikse ${ }^{1,7}$. Jacqueline G. Hugtenburg ${ }^{1,2}$
}

Received: 11 October 2019 / Accepted: 22 May 2020 / Published online: 2 June 2020

(C) The Author(s) 2020

\begin{abstract}
Introduction This comprehensive observational study aimed to gain insight into adherence to nilotinib and the effect of (non)adherence on exposure $\left(C_{\mathrm{min}}\right)$ and treatment outcomes.

Methods Chronic myeloid leukemia (CML) patients using nilotinib were followed for 12 months. Adherence was measured by Medication Event Monitoring System (MEMS), pill count, and Medication Adherence Report Scale (MARS-5). Nilotinib $C_{\text {min }}$ and patient-reported outcomes (i.e., quality of life, side effects, beliefs, satisfaction) were measured at baseline, 3, 6, and 12 months. Results Sixty-eight patients ( $57.5 \pm 15.0$ years, $49 \%$ female) participated. Median adherence to nilotinib (MEMS and pill count) was $\geq 99 \%$ and adherence $<90 \%$ was rare. Self-reported nonadherence (MARS-5) increased in the first year of treatment to a third of patients. In line with the strong beliefs in the necessity of taking nilotinib, forgetting to take a dose was more prevalent than intentionally adjusting/skipping doses. Nilotinib $C_{\min }$ were generally above the therapeutic target in $95 \%$ of patients. Patients reported a variety of side effects, of which fatigue was most frequent. The mean $C_{\min }$ was higher in patients who reported severe itching and fatigue. The overall 1-year MMR rate ranged from 47 to $71 \%$.

Conclusion Substantial nonadherence $(<90 \%)$ to nilotinib was rare and nilotinib $C_{\min }$ were generally above the therapeutic target. Lack of response in our group of patients was not related to nonadherence or inadequate $C_{\min }$. Nevertheless, a considerable number of patients experienced difficulties in adhering to the twice daily fasted dosing regimen, emphasizing the importance of continuous support of medication adherence in CML.
\end{abstract}

Clinical trial registration NTR3992 (Netherlands Trial Register, www.trialregister.nl)

Keywords Chronic myeloid leukemia · Nilotinib · Medication adherence · Patients' experiences · Plasma concentration · Molecular response · Treatment outcome

Electronic supplementary material The online version of this article (https://doi.org/10.1007/s00228-020-02910-3) contains supplementary material, which is available to authorized users.

Christel C. L. M. Boons

c.boons@amsterdamumc.nl

1 Department of Clinical Pharmacology and Pharmacy, Amsterdam UMC, Vrije Universiteit Amsterdam, Cancer Centre Amsterdam, De Boelelaan 1117, 1081 HV Amsterdam, The Netherlands

2 Amsterdam Public Health Research Institute, Amsterdam UMC, Vrije Universiteit Amsterdam, De Boelelaan 1117, 1081 HV Amsterdam, The Netherlands

3 Department of Hematology, Amsterdam UMC, Vrije Universiteit Amsterdam, Cancer Centre Amsterdam, De Boelelaan 1117, 1081 HV Amsterdam, The Netherlands
4 Department of Hematology, Albert Schweitzer Ziekenhuis, Albert Schweitzerplaats 25, 3318 AT Dordrecht, The Netherlands

5 Department of Hematology, Radboudumc, Geert Grooteplein Zuid 10, 6525 GA Nijmegen, The Netherlands

6 Department of Hematology, Medisch Spectrum Twente, Koningsplein 1, 7512 KZ Enschede, The Netherlands

Department of Radiology and Nuclear Medicine, Amsterdam UMC, Vrije Universiteit Amsterdam, Cancer Centre Amsterdam, De Boelelaan 1117, 1081 HV Amsterdam, The Netherlands 


\section{Introduction}

Newly diagnosed patients with chronic-phase chronic myeloid leukemia (CP-CML) are treated with tyrosine kinase inhibitors (TKI) including imatinib, dasatinib, nilotinib, or bosutinib which specifically block BCR-ABL activity [1]. Dasatinib, nilotinib, and bosutinib are so-called second-generation TKIs (2G-TKIs) that are more potent than imatinib. Clinical study data show that the overall survival of CP-CML patients achieving a major molecular response (MMR) on TKI treatment now resembles that of the general population $[2,3]$. However, side effects like fatigue, edema, skin toxicity, accelerated cardiovascular disease, pleural effusion, and pulmonary hypertension may cause significant morbidity and reduce quality of life [4-6].

CP-CML treatment discontinuation may be attempted in patients attaining a deep molecular response at the level of $\mathrm{MR}^{4}$ or better $[1,7]$. However, not all patients achieve these response levels. Causes include the presence of point mutations in the kinase domain of the BCR-ABL protein, increased BCR-ABL protein expression, and increased drug efflux mechanisms $[8,9]$. In addition, pharmacokinetic factors like interindividual variabilities in the liver (CYP3A4) metabolism and plasma protein binding, or interactions with other drugs, may lead to suboptimal plasma drug concentrations that affect response rates [10-16]. In this respect, lower trough plasma concentrations $\left(C_{\min }\right)$ have been associated with a failure to achieve key response milestones and a shorter time to progression in both newly diagnosed and imatinib-resistant or imatinib-intolerant CP-CML patients [12-15]. On the other hand, supratherapeutic TKI levels have been shown to increase toxicity. For example, high nilotinib peak plasma concentrations that may occur when the drug is taken with food may increase the QTc interval [16].

Next to these disease-related and pharmacokinetic factors, a major factor to treatment failure is medication nonadherence [17-22]. Several studies show that for imatinib, an adherence rate (mostly expressed by the Medication Possession Ratio [MPR]) of at least $90 \%$ is required to achieve an adequate (molecular) response and that nonadherent patients have a significantly reduced chance of reaching key response milestones [17-22]. For the 2G-TKIs, data on the minimum adherence required to achieve the intended medication effect are not available. The majority of data on adherence to 2G-TKIs have been obtained in retrospective studies [23-35], with only one study investigating adherence prospectively [36]. The average adherence rates range from 69 to $100 \%$ [23-36]. A wide variety of (interrelated) factors is known to influence adherence in CML. They include the choice of the medication, convenience of the dosing regimen, treatment duration, treatment effectiveness, occurrence of side effects affecting quality of life, patient beliefs, patient knowledge and understanding, disease characteristics (e.g., disease severity, comorbidity and comorbidity treatment, mental status), life style, communication with healthcare providers (HCP), and affordability of treatment [37-39]. Clearly, a better understanding of the variables affecting (non)adherence is necessary to optimize treatment conditions to a level that enables patients to use their prescribed medication as long as required while preserving the highest possible quality of life $[37,38,40]$.

Most CP-CML patients have to take their oral medication indefinitely. In this respect, for patients taking nilotinib, the necessary twice daily fasted schedule is an additional burden that may trigger nonadherence. The RAND study (Response and Adherence to Nilotinib in Daily practice) was conducted with the aim to gain insight into nilotinib treatment adherence in daily clinical practice and the effect of (non)adherence on nilotinib exposure and treatment outcomes. Multiple measures were used to assess adherence including electronic monitoring, pill count and questionnaires, and factors influencing adherence including patient characteristics, side effects, quality of life, attitudes towards disease and treatment, and satisfaction with information were studied. Furthermore, we evaluated nilotinib exposure and its relationship with side effects and treatment outcome.

\section{Methods}

\section{Study design}

In this multicenter prospective observational study [41], conducted between August 2013 and April 2017 in six Dutch hospitals, CP-CML patients using nilotinib were followed for 12 months. Initially, it was the aim only to include newly diagnosed CP-CML patients starting nilotinib treatment. However, because of poor participant accrual, the protocol was amended in September 2014 and patients on treatment with nilotinib (and regardless of prior TKI treatment) were also included. The study was registered in the Netherlands Trial Register (NTR3992) and the protocol has been published previously [41].

\section{Patients}

The study population consisted of patients (aged $\geq 18$ years) with CP-CML using nilotinib [42]. According to the line of treatment (first- or second/third-line) and the type of nilotinib treatment at baseline (starting treatment or already being on treatment), four groups of patients were distinguished. Exclusion criterion was the inability to grant consent. 


\section{Data collection}

\section{Medication adherence}

Medication adherence has been defined as "the process by which patients take their medications as prescribed", divided into three phases: initiation, implementation, and discontinuation [43]. The RAND study focused on the implementation phase and used three methods to assess adherence to nilotinib.

First, adherence was assessed by means of a medication event monitoring system (MEMS; AARDEX Group, Switzerland). Capsules were stored in a bottle closed by a lid containing the MEMS monitoring the date and time of opening. Each opening was presumed to indicate the intake of a dose, with a maximum of two intakes per day. Patients knew that dosing data were compiled by means of the MEMS. To minimize bias, patients were instructed that nilotinib use in general was studied and the study aim of measuring adherence was deliberately omitted in the patient information. Adherence was expressed as the proportion of days covered (PDC) and calculated by the number of times that the bottle had been opened divided by the total number of intakes prescribed over the period that the MEMS was used times $100 \%$.

Second, adherence was assessed by means of pill count. Patients were contacted unannounced by the researcher by phone at study entry and at the end of the follow-up period to count the number of capsules at that moment. Patients were asked whether they had returned capsules to the pharmacy or disposed capsules in any other way. Pharmacy dispensing records and the prescribed number of capsules retrieved from the patient's medical file were collected. Adherence was expressed as the adherence rate (AR) and calculated by dividing the number of capsules dispensed minus the pill count by the number of capsules prescribed over the study period times $100 \%$ [33].

Third, the five-item Medication Adherence Report Scale (MARS-5) was used to assess self-reported adherence [44-46]. The MARS-5 was administered at 3, 6, and 12 months from study entry. Items are scored using a 5-point scale ( $1=$ always to $5=$ never). Scores for each item were summed to give a total score ranging from 5 to 25 , with higher scores indicating higher levels of adherence. A self-composed question assessed nilotinib intake in relation to food intake. Nilotinib intake under fasting conditions was scored as incorrect when patients reported to have taken nilotinib $<60 \mathrm{~min}$ before or $<120 \mathrm{~min}$ after food intake.

\section{Trough plasma concentration}

Blood sampling was performed by the patient at home by means of a validated dried blood spot (DBS) sampling method. Using the DBS, nilotinib plasma concentrations were calculated as previously reported [47, 48]. Patients were instructed to sample blood at predose at baseline (if already on nilotinib treatment), 3, 6, and 12 months from study entry. The time of blood sampling, time of last nilotinib intake, and body weight were recorded in patient diaries. $C_{\text {min }}$ samples were defined as those taken between 8 and $16 \mathrm{~h}$ after the prior dose.

\section{Response to treatment}

The response was considered optimal when a MMR was achieved within 12 months of nilotinib treatment [1, 42]. MMR was defined as a BCR-ABL transcript level of $\leq 0.1 \%$ on the International Scale. For patients already on treatment at entry, the time until MMR was obtained retrospectively from their medical files.

\section{Questionnaires}

At study entry, patients completed a self-administered composite questionnaire including demographic characteristics (date of birth, gender, education, living status, and working status), use of St. John's wort, use of grapefruit (juice), quality of life (Short Form-12 Health Survey [SF-12]), side effects, and beliefs about medication in general (Beliefs about Medicines Questionnaire [BMQ]-General) and specifically about nilotinib (BMQ-Specific) [49, 50]. The questionnaire at 3, 6, and 12 months also included the MARS-5 and questions on nilotinib intake in relation to food intake, use of tools to prevent forgetting, illness perception (Brief Illness Perception Questionnaire [Brief IPQ]), and information satisfaction (Satisfaction with Information about Medicines Scale [SIMS])[51, 52]. Education was assessed as the highest level completed, and dichotomized into higher education (higher general secondary education or above) and lower education. Living status was categorized as living alone or not living alone, and work status as having paid work or not. Questions on side effects were based on literature data and concerned specific nilotinib toxicities occurring in $>10 \%$ of patients (headache, nausea, rash, itching, myalgia, fatigue) [53]. Answers were scored on a 5-point Likert scale $(0=$ not at all to 4 = very much). Symptoms scored as " $3=$ a lot" or " 4 = very much" were considered "severe."

\section{Disease and treatment characteristics}

Information on disease characteristics, medical history, comedication, and nilotinib treatment was obtained from the patient's medical file and pharmacy dispensing record.

\section{Statistical analysis}

Differences in patient and clinical characteristics between the four groups were tested (continuous variables by Mann- 
Whitney tests and categorical variables by chi-square tests). Adherence was summarized by median and mean PDC (MEMS), AR (pill count), and MARS-5 scores, and the number of nonadherent patients according to various adherence cut-off points. Agreement between the adherence measures was examined using intra-class correlation coefficient (ICC, two-way mixed effects model) comparing MEMS (\% PDC) with pill count ( $\%$ AR) and Cohen's Kappa comparing MEMS and pill count (dichotomized at thresholds of $90 \%$ and $95 \%$ ) with MARS-5. Change over time in dichotomized MARS-5 scores was assessed using generalized estimating equation (GEE) and univariable logistic regression was used to identify variables (one by one) related to self-reported nonadherence (MARS-5 $<25$ at 12 months). Variables related to incorrect intake of nilotinib under fasting conditions were identified using logistic regression (baseline characteristics) and GEE (repeatedly measured variables).

Individual measures of exposure were obtained using averaged $C_{\min }$ values for individual patients based on the measurements obtained at baseline, 3, 6, and 12 months. Intrapatient variability in nilotinib $C_{\min }$ was analyzed in patients who had $\geq 2$ analyzed samples available and expressed as the average coefficient of variation (CV\%). Missing $C_{\min }$ values were imputed with the mean of the observed $C_{\min }$ values for the corresponding dose. Univariable linear regression was used to identify variables (one by one) related to nilotinib $C_{\text {min }}$. GEE was used to identify whether the occurrence of side effects was related to observed nilotinib $C_{\min }$ values (without imputation) obtained at baseline, 3, 6, and 12 months.

Comparison of adherence (continuous) and $C_{\min }$ values (either grouped into quartiles [Q1 vs. Q2-Q4] or based on a previously reported [13] threshold concentration of $490 \mu \mathrm{g} / \mathrm{L}$ ) among response groups (time to MMR after start of nilotinib treatment $\leq 12$ months vs. $>12$ months, stratified by line of treatment) was performed using Mann-Whitney tests and Fisher's exact tests. Time to MMR was assessed using the Kaplan Meier method with logrank test. In these outcome analyses, the mean of each measure of adherence and $C_{\text {min }}$ values was used. For all analyses, a two-tailed significance level of 0.05 was used. $p$ values below this level were considered statistically significant. All statistical analyses were performed using SPSS version 22 for Windows (IBM Corp, Armonk, NY, USA).

\section{Results}

\section{Study sample}

A total of 68 patients (mean age $57.5 \pm 15.0$ years, $49 \%$ female) were included. Thirty-five patients $(51 \%)$ received firstline nilotinib treatment, of whom 20 (29\%) started treatment (subpopulation 1A) and $15(22 \%)$ already were on treatment at baseline with a median duration of 40 months (range 7-51) (subpopulation 1B). Thirty-three patients (49\%) received second/third-line nilotinib treatment, of whom 9 (13\%) started treatment (subpopulation 2A) and 24 (35\%) already were on treatment at baseline with a median duration of 43 months (range 7-51) (subpopulation 2B). Fifteen patients $(22 \%)$ discontinued nilotinib treatment during the study period due to side effects $(n=6)$, progression $(n=4)$, entering treatmentfree remission $(n=4)$, or death $(n=1)$. Their characteristics (demographics, medical history, nilotinib dose) did not differ from those of patients who completed follow-up. Five patients dropped out before assessment at 3 months, two patients before 6 months, and eight patients before 12 months. Figure 1 provides information on the number of patients for whom data are available.

\section{Patient characteristics}

Patients' characteristics are presented in Table 1. There were no statistically significant differences $(p>0.05)$ with regard to patient demographics, medical history, and nilotinib dose between the four subpopulations, except for a small difference in the median number of co-medications between subpopulations $1 \mathrm{~A} / 1 \mathrm{~B}$ and $2 \mathrm{~A} / 2 \mathrm{~B}$ ( 1 vs. $3, p=0.043$ ). Most patients $(49 / 68,72 \%)$ used the recommended dose of $300 \mathrm{mg}$ BID. The other patients used a dose of $150 \mathrm{mg}$ BID $(n=5), 400 \mathrm{mg}$ $\mathrm{BID}(n=9), 300 \mathrm{mg}$ QD $(n=2)$, and $400 \mathrm{mg}$ QD $(n=3)$. In three patients, the dose was reduced during the study period. The percentage of patients with co-medication was $73 \%$. No patient reported using St. John's wort. Based on the declared co-medications, there were no drug-drug interactions.

Patients' SF-12 scores for physical health measured at 6 months ranged from 17.1 to 58.4 (standardized scale 0-100 [Supplementary Table S1]). The median and mean scores were 45.4 and $44.1 \pm 11.5$, respectively. The SF-12 scores for mental health ranged from 27.3 to 61.8, with median and mean scores of 40.0 and $41.8 \pm 6.9$, respectively. About $75 \%$ of the patients experienced fatigue, which was severe in $20 \%$ (Supplementary Table S1). Rash, itching, and myalgia were reported by $43 \%, 59 \%$, and $54 \%$ of the patients, respectively, and $8 \%, 8 \%$, and $6 \%$ indicated these symptoms as severe. Headache and nausea were less common and generally mild.

The BMQ scores indicated that patients had strong beliefs about the necessity of taking nilotinib $(20.5 \pm 3.4)$ and low concerns about CML and the potential adverse effects of nilotinib $(12.9 \pm 3.4)$. The majority of patients had an accepting $(65 \%)$ or ambivalent $(30 \%)$ attitude towards nilotinib (Supplementary Table S1). Regarding illness perception, the high medians on the timeline $(10 / 10)$, treatment control (10/10), and coherence (8/10) subscales indicate that patients were fully aware of the lifelong duration of CML, strongly believed in the effectiveness of nilotinib, and felt a strong coherent understanding of CML. The low median on 


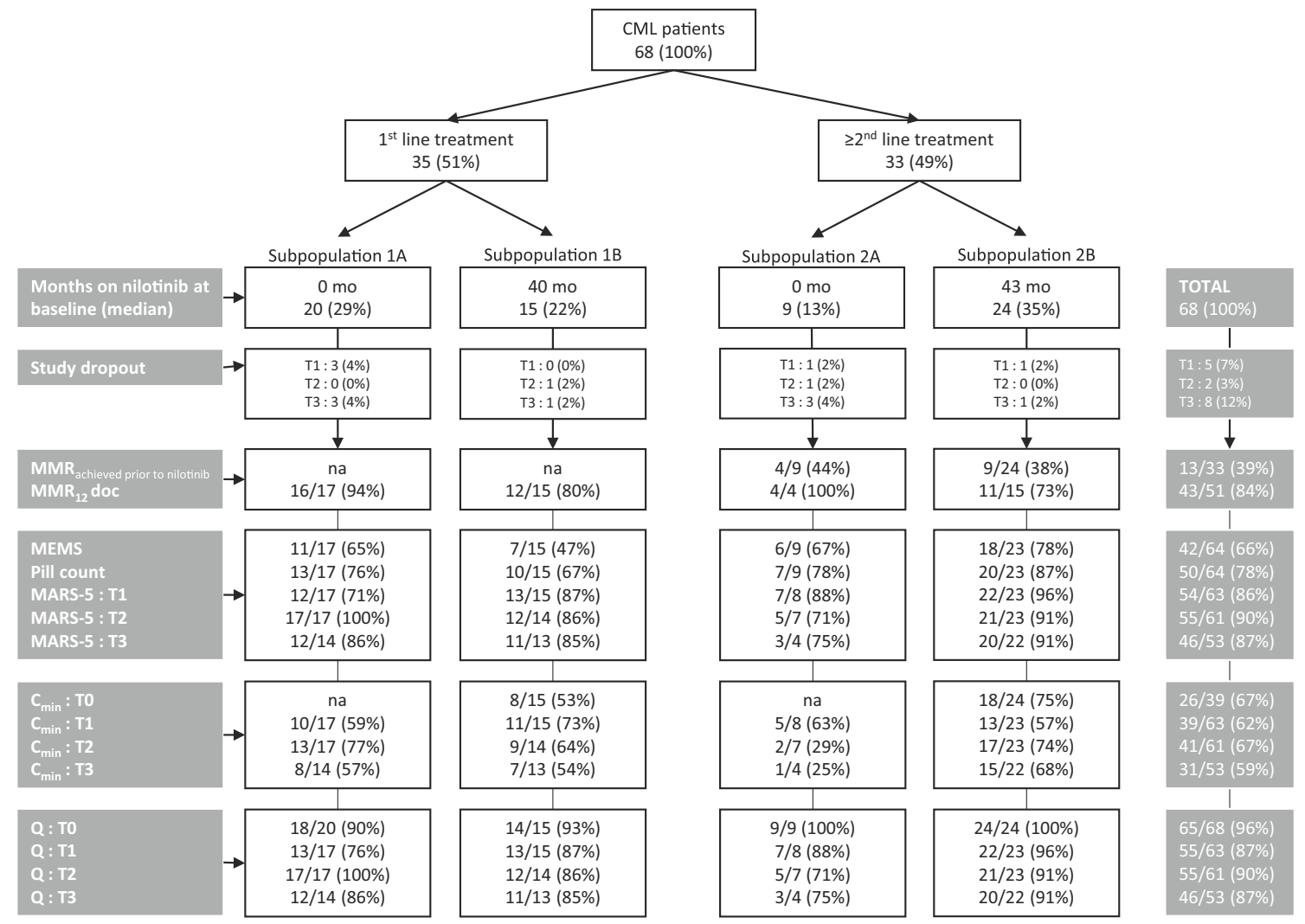

Fig. 1 RAND study flow chart

the emotional response $(3 / 10)$ subscale indicated that patients perceived only little emotional distress from CML.

\section{Adherence to nilotinib treatment}

Data on adherence to nilotinib treatment are shown in Table 2. Adherence by means of MEMS was available for 42 patients, and monitored over a mean of $307 \pm 113$ days. Eight patients were not willing to use MEMS (as it would disturb their daily routines too much), three patients did not return their MEMS, and eleven patients returned MEMS with no data (either due to MEMS malfunction or patient refusal). Four patients discontinued nilotinib treatment within 4 days from study entry. The median and mean PDC from baseline to follow-up were $99.0 \%$ and $95.7 \pm 8.5 \%$, respectively (from 54.6 to $100 \%)$. Five patients $(5 / 42,12 \%)$ covered less than $90 \%$ of days observed. Adherence by means of pill count could be determined for 50 patients. For the remaining patients, the pill count was missing $(n=9)$, pharmacy data were incomplete $(n$ $=5$ ), or treatment was stopped within 4 days from study entry $(n=4)$. The median and mean AR were $99.8 \%$ and $98.3 \pm$ $8.7 \%$, respectively (from 67.3 to $125.6 \%$ ). Five patients (5/50, $10 \%)$ had an AR $<90 \%$. Five patients $(5 / 50,10 \%)$ had an AR $>105 \%$.

The percentage of patients reporting nonadherence on any of the five MARS-5 statements after 12 months was $32 \%$.
Median and mean MARS- 5 scores of the nonadherent patients were 24 and $23.3 \pm 1.0$, respectively. The most common statement was "I forget to take it" varying from 17 to $26 \%$. The statements "I alter the dose," "I stop taking it for a while," and "I decide to miss out on a dose" were reported by $\leq 6 \%$. Seventeen patients $(27 \%)$ did not always correctly take nilotinib under fasting conditions (i.e., $<60 \mathrm{~min}$ before or $<$ $120 \mathrm{~min}$ after food intake). No patient reported to have taken nilotinib simultaneously with food or to have used grapefruit (juice) during nilotinib treatment. Most patients (87\%) reported to have used a tool to remind them of the scheduled nilotinib intake (e.g., fixed place/moment, alarm, diary, support from family/friends).

Agreement between MEMS (\% PDC) and pill count (\% AR) was poor, with an ICC of $0.14(p=0.801)$ (Table 2). Regarding dichotomized MARS-5 scores (25 vs. $<25)$, only adherence by means of MEMS dichotomized at a threshold of 95\% showed moderate agreement, with Cohen's Kappa varying from 0.29 to $0.47(p<0.1)$.

The number of patients reporting nonadherence (MARS-5 data) increased over time for patients starting nilotinib firstline treatment (subpopulation 1A) from $8 \%$ after 3 months of treatment to $33 \%$ after 12 months. In the other three subpopulations, the percentage of patients ranged from 27 to $37 \%$. This group-by-time interaction effect was close to significance $(p=0.066)$. Self-reported nonadherence was not associated 
Table 1 Patient demographics and clinical status at baseline

\begin{tabular}{|c|c|c|c|}
\hline & & $\begin{array}{l}1 \text { st line treatment } \\
n=35\end{array}$ & $\begin{array}{l}\geq 2 \text { nd line treatment } \\
n=33\end{array}$ \\
\hline \multicolumn{4}{|c|}{ Patient demographics } \\
\hline \multicolumn{2}{|c|}{ Age, mean $\pm \mathrm{SD}$ (years) } & $55.7 \pm 15.0$ & $59.3 \pm 14.9$ \\
\hline \multicolumn{2}{|c|}{ Female gender, $n(\%)$} & $15(43 \%)$ & $18(55 \%)$ \\
\hline \multicolumn{2}{|c|}{ Higher level of education, $n(\%)$} & $7(20 \%)$ & $12(36 \%)$ \\
\hline \multicolumn{2}{|c|}{ Living alone, $n(\%)$} & $7(20 \%)$ & $2(6 \%)$ \\
\hline \multicolumn{2}{|c|}{ Employed, $n(\%)$} & $18(51 \%)$ & $12(36 \%)$ \\
\hline \multicolumn{4}{|c|}{ Medical history } \\
\hline \multicolumn{2}{|c|}{ History of other malignancy, $n(\%)$} & $7(20 \%)$ & $7(21 \%)$ \\
\hline \multicolumn{2}{|c|}{ Presence of comorbidity, $n(\%)$} & $16(46 \%)$ & $22(67 \%)$ \\
\hline \multicolumn{2}{|c|}{ Co-medication, range, median (IQR) * } & $0-12,1(0-4)$ & $0-11,3(1-5)$ \\
\hline \multicolumn{2}{|c|}{ No. of patients with $\geq 1$ co-medication } & $22(63 \%)$ & $28(85 \%)$ \\
\hline \multicolumn{4}{|c|}{ History of CML and treatment } \\
\hline \multicolumn{2}{|c|}{ Years since CML diagnosis, range, median (IQR) } & $1-4,3.4(1.2-3.9)^{\mathrm{a}}$ & $1-22,7.6(5.0-10.5)$ \\
\hline \multicolumn{4}{|c|}{ Prior TKI treatment and outcome, $\mathrm{n}(\%)$} \\
\hline \multicolumn{2}{|c|}{ Imatinib } & NA & $32(97 \%)$ \\
\hline \multicolumn{2}{|c|}{ Failure } & & $22(69 \%)$ \\
\hline \multicolumn{2}{|c|}{ Intolerance } & & $9(28 \%)$ \\
\hline \multicolumn{2}{|c|}{ Unknown } & & $1(3 \%)$ \\
\hline \multicolumn{2}{|c|}{ Dasatinib } & NA & $12(36 \%)$ \\
\hline \multicolumn{2}{|c|}{ Failure } & & $4(33 \%)$ \\
\hline \multicolumn{2}{|c|}{ Intolerance } & & $8(66 \%)$ \\
\hline \multicolumn{4}{|c|}{ Disease parameters at baseline } \\
\hline \multicolumn{4}{|c|}{ Hematological response, $n(\%)$} \\
\hline \multicolumn{2}{|c|}{ Too early to judge } & $20(57 \%)$ & - \\
\hline \multicolumn{2}{|l|}{ CHR } & $13(37 \%)$ & $29(88 \%)$ \\
\hline \multicolumn{2}{|c|}{ No CHR } & $2(6 \%)$ & $3(9 \%)$ \\
\hline \multicolumn{2}{|c|}{ Not documented } & - & $1(3 \%)$ \\
\hline Molec & $(\%)$ & & \\
\hline Too e & & $20(57 \%)$ & - \\
\hline $\mathrm{MR}^{4}$ & $01 \%)$ & $10(29 \%)$ & $10(30 \%)$ \\
\hline Majo & $\leq 0.1 \%)$ & $1(3 \%)$ & $9(27 \%)$ \\
\hline $\mathrm{BCR}-$ & & $3(9 \%)$ & $10(30 \%)$ \\
\hline Not d & & $1(3 \%)$ & $4(12 \%)$ \\
\hline Nilotin & aseline & & \\
\hline Month & nge, median (IQR) & $7-51,40(15-46)^{\mathrm{a}}$ & $4-92,43(25-55)^{\mathrm{a}}$ \\
\hline Dose & 300 mg/day, $n(\%)$ & $2(6 \%)$ & $5(15 \%)$ \\
\hline & $400 \mathrm{mg} / \mathrm{day}, n(\%)$ & - & $3(9 \%)$ \\
\hline & $600 \mathrm{mg} / \mathrm{day}, n(\%)$ & $32(91 \%)$ & $17(52 \%)$ \\
\hline & 800 mg/day, $n(\%)$ & $1(3 \%)$ & $8(24 \%)$ \\
\hline
\end{tabular}

Abbreviations: $C H R$, complete hematological response; $C M L$, chronic myeloid leukemia; $I Q R$, interquartile range; $M R$, molecular response; $N A$, not applicable; $S D$, standard deviation; $T K I$, tyrosine kinase inhibitor *Difference between groups significant $(p \leq 0.05)$

${ }^{\text {a }}$ Patients already being on treatment at baseline, $n=15$ (1st line) $n=24$ ( $\geq 2$ nd line) with differences in disease and treatment characteristics, occurrence of side effects, and SF-12, Brief IPQ, BMQ-Specific, and SIMS scores (Supplementary Table S2). Regarding demographics, only gender was associated with self-reported nonadherence. Female patients more often reported nonadherence $(44 \%$ vs. $13 \%$ in male patients, OR 5.1, $95 \%$ CI $1.2-22.2, p=0.029)$. As only few patients had an PDC (MEMS data) or AR (pill count data) below 90\%, no 
Table 2 Adherence to nilotinib treatment

\begin{tabular}{llll}
\hline & Mean \pm SD & Median (IQR) & Range \\
\hline $\begin{array}{l}\text { Adherence by means of MEMS }(n=42) \\
\text { PDC, from baseline to follow-up }\end{array}$ & $95.7 \pm 8.5$ & $99.0(95.6-99.6)$ & $54.6-100$ \\
$100 \%$ & $6(14.4 \%)$ & & \\
$\geq 95<100 \%$ & $27(64.3 \%)$ & & \\
$\geq 90<95 \%$ & $4(9.5 \%)$ & & \\
$<90 \%$ & $5(11.9 \%)$ & & \\
Adherence by means of pill count $(n=50)$ & & & \\
AR, from baseline to follow-up & $98.3 \pm 8.3-125.6$ \\
& $5(10.0 \%)$ & & \\
$>105 \%$ & $35(70.0 \%)$ & & \\
$\geq 95 \%-\leq 105 \%$ & $5(10.0 \%)$ & & \\
$\geq 90<95 \%$ & $5(10.0 \%)$ & $21-25(24-25)$ \\
$<90 \%$ & &
\end{tabular}

Agreement of adherence assessment methods ${ }^{\mathrm{a}}$

MEMS (continuous)

Pill count (continuous) $(n=36)$

ICC $p$

$0.14 \quad .801$

MARS-5 (dichotomous, $<25$ vs. 25$)\left(n=34^{\text {mems }} ; n=38^{\text {pill count }}\right)$

K

$p$

MEMS (dichotomous) $\quad<90 \%$ vs. $\geq 90 \% \quad 0.04 \quad .778$

$<95 \%$ vs. $\geq 95 \% \quad 0.41 \quad .014$

Pill count (dichotomous) $\quad<90 \%$ vs. $\geq 90 \% \quad-0.03 \quad .854$

$<95 \%$ vs. $\geq 95 \% \quad-0.04 \quad .782$

Abbreviations: $A R$, adherence rate; MARS-5, Medication Adherence Report Scale, at $\geq 12$ months of treatment; $M E M S$, Medication Event Monitoring System; $P D C$, proportion of days covered; $S D$, standard deviation; $I Q R$, interquartile range; $I C C$, intra-class correlation coefficient; $K$, Kappa

${ }^{a}$ Analyses of continuous outcomes using ICC and dichotomous outcomes using Cohen's Kappa factors could be analyzed for their relationship with nonadherence as assessed by MEMS or pill count. No association was found between all variables and incorrect intake of nilotinib under fasting conditions (Supplementary Table S2).

\section{Nilotinib $C_{\min }$}

A total of 178 DBS samples were collected by 61 patients. Thirty-five samples (19.7\%) were rejected because the spot size was too small for analysis. Six samples $(3.4 \%)$ had been obtained within $8 \mathrm{~h}$ of nilotinib intake and therefore were excluded as $C_{\min }$ [48]. As the result, $137 C_{\min }$ values from 56 patients were obtained (Table 3 ). Forty-two patients (72\%) had $\geq 2$ analyzed samples available, and the $\% \mathrm{CV}$ in $C_{\min }$ amounted to $25 \pm 19 \%$ (median $20 \%$; range $1-91 \%$ ). No association was found between all measures of adherence and nilotinib $C_{\text {min }}$ (Table 3). Age, gender, body weight, incorrect intake of nilotinib under fasting conditions, and intra-patient variability were also not significantly related to the nilotinib $C_{\min }$. A positive linear association between nilotinib dose and $C_{\min }$ was found $(\beta=0.44, p<0.001)$.

The relationship between the nilotinib $C_{\min }$ value and patient-reported side effects is presented in Table 4 . The mean $C_{\min }$ was significantly higher in patients who reported severe itching $(p=0.012)$ and fatigue $(p=0.023)$. With regard to fatigue, there was a significant difference in $C_{\min }$ between patients reporting any severity fatigue and those without fatigue $(p$ $=0.007)$. The median nilotinib dose was $600 \mathrm{mg}$ in all side effect groups. No relationship with other side effects was found.

\section{Molecular response to nilotinib treatment}

For patients on first-line nilotinib treatment (subpopulations 1A/1B), the 1-year MMR rate was 71\% (20/28) (note, four 
Table 3 Associations with nilotinib $C_{\min }$

\begin{tabular}{|c|c|c|c|c|}
\hline \multicolumn{2}{|l|}{ Observed nilotinib $C_{\min }(\mu \mathrm{g} / \mathrm{L})$} & Mean \pm SD & Median (IQR) & Range \\
\hline \multicolumn{2}{|l|}{$400 \mathrm{mg} \operatorname{BID}(n=25)$} & $1497 \pm 597$ & $1253(1054-2053)$ & $342-2540$ \\
\hline \multicolumn{2}{|l|}{$300 \mathrm{mg} \operatorname{BID}(n=85)$} & $1021 \pm 472$ & $954(654-1274)$ & $196-2413$ \\
\hline \multicolumn{2}{|l|}{$150 \mathrm{mg} \operatorname{BID}(n=15)$} & $835 \pm 412$ & $656(548-1042)$ & $390-1793$ \\
\hline \multicolumn{2}{|l|}{$400 \mathrm{mg}$ QD $(n=6)$} & $536 \pm 57$ & $552(517-570)$ & $422-574$ \\
\hline \multicolumn{2}{|l|}{$300 \mathrm{mg}$ QD $(n=6)$} & $567 \pm 110$ & $589(450-658)$ & $418-702$ \\
\hline \multicolumn{2}{|l|}{ Associations with nilotinib $C_{\min }{ }^{\mathrm{a}}$} & $\beta$ & $p$ & \\
\hline \multicolumn{2}{|l|}{ Age } & 0.08 & .534 & \\
\hline \multicolumn{2}{|l|}{ Female gender } & 0.05 & 687 & \\
\hline \multicolumn{2}{|l|}{ Body weight } & 0.03 & .982 & \\
\hline \multicolumn{2}{|l|}{ Dose } & 0.44 & $<.001$ & \\
\hline \multicolumn{2}{|l|}{$\mathrm{CV} \%$} & 0.23 & .154 & \\
\hline \multirow[t]{3}{*}{ Incorrect intake under fasting conditions ${ }^{\mathrm{b}}$} & $\mathrm{T} 1$ & -0.07 & .712 & \\
\hline & $\mathrm{T} 2$ & -0.01 & .949 & \\
\hline & $\mathrm{T} 3$ & 0.21 & .297 & \\
\hline \multirow[t]{5}{*}{ Adherence to nilotinib ${ }^{\mathrm{b}}$} & MEMS & -0.05 & .763 & \\
\hline & Pill count & -0.13 & .396 & \\
\hline & MARS-5 T1 & 0.13 & .466 & \\
\hline & MARS-5 T2 & 0.05 & .753 & \\
\hline & MARS-5 T3 & -0.14 & .472 & \\
\hline
\end{tabular}

Abbreviations: $B I D$, twice daily; $Q D$, once daily; $C_{m i n}$, trough plasma concentration; $C V \%$, coefficient of variation; MARS-5, Medication Adherence Report Scale; MEMS, Medication Event Monitoring System; $S D$, standard deviation; $I Q R$, interquartile range. Significant relations are shown in italic $(p<0.05)$

${ }^{\text {a }}$ BID dosing, $C_{\min }$ samples were taken between 8 and $16 \mathrm{~h}$ after the prior dose $(n=125)$

${ }^{\mathrm{b}}$ Incorrect intake of nilotinib under fasting conditions and MARS-5 was related to observed $C_{\min }$ values at 3 (T1), 6 (T2), and 12 (T3) months from baseline missing). The median and mean times to $\mathrm{MMR}_{12}$ were 6.1 and $5.9 \pm 3.2$ months, respectively (range 1.2-12.9 months). Two patients discontinued nilotinib treatment before achieving a MMR due to side effects and one patient died. For patients on second/third-line nilotinib treatment (subpopulations $2 \mathrm{~A} /$ 2B), the 1-year MMR rate was 47\% (7/15) (note, four missing). The median and mean times to $\mathrm{MMR}_{12}$ were 3.7 and $5.8 \pm 4.4$ months, respectively (range 2.6-12.4 months). One patient discontinued nilotinib treatment before achieving a MMR due to side effects. Thirteen patients had achieved a MMR prior to nilotinib treatment, of whom seven patients a deep $\mathrm{MR}^{4}$.
Table 4 Nilotinib $C_{\min }$ and patient-reported side effects of nilotinib $^{\mathrm{a}}$

\begin{tabular}{|c|c|c|c|c|c|c|c|c|}
\hline & \multicolumn{2}{|c|}{ None } & \multicolumn{2}{|c|}{ Mild $^{\mathrm{b}}$} & \multicolumn{2}{|c|}{ Severe $^{\mathrm{b}}$} & \multicolumn{2}{|l|}{$p$} \\
\hline & $n$ & $\begin{array}{l}C_{\min }(\mu \mathrm{g} / \mathrm{L}) \\
\text { median }(\mathrm{IQR})\end{array}$ & $n$ & $\begin{array}{l}C_{\min }(\mu \mathrm{g} / \mathrm{L}) \\
\text { median }(\mathrm{IQR})\end{array}$ & $n$ & $\begin{array}{l}C_{\min }(\mu \mathrm{g} / \mathrm{L}) \\
\text { median }(\mathrm{IQR})\end{array}$ & Any & Severe \\
\hline Headache & 91 & $970(618-1288)$ & 40 & $905(625-1254)$ & 1 & 2413 & .964 & - \\
\hline Nausea & 104 & 945 (615-1249) & 27 & $1210(750-1798)$ & 1 & 648 & .151 & - \\
\hline Rash & 75 & $964(598-1338)$ & 45 & 966 (719-11620 & 12 & $1157(764-1540)$ & .418 & .746 \\
\hline Itching & 61 & $954(565-1283)$ & 61 & $923(740-1243)$ & 11 & $1260(1021-1800)$ & .938 & .012 \\
\hline Myalgia & 56 & 857 (574-1219) & 62 & $1031(765-1380)$ & 12 & $840(658-1553)$ & .387 & .399 \\
\hline Fatigue & 32 & 777 (561-1087) & 72 & $974(644-1373)$ & 25 & $1160(787-1468)$ & .007 & .023 \\
\hline
\end{tabular}

Abbreviations: $C_{\min }$, trough plasma concentration; $I Q R$, interquartile range. Significant relations are shown in italic $(p<0.05)$

${ }^{a}$ Analyses using generalized estimated equations (GEE)

b Side effects scored as "a little bit"/"rather" were considered "mild"; side effects scored as "a lot"/"very much" were considered "severe" 
Patients who achieved a MMR within 12 months after having started nilotinib treatment had similar adherence rates (mean PDC $95.0 \pm 8.7 \%$ ) as those who failed to obtain a MMR within 12 months of treatment (mean PDC $94.6 \pm$ $11.9 \%, p=0.683$ ) (Table 5). Among patients treated with either first-line or second/third-line nilotinib, no significant differences in mean adherence were found between the response groups. There were no significant differences between response groups in self-reported adherence (MARS-5) (data not shown).

Among the evaluable patients, the MMR rate was not significantly different between $C_{\text {min }}$ quartiles (Table 5). The median time to $\mathrm{MMR}_{12}$ was $6.4(\mathrm{Q} 1, n=5), 6.7(\mathrm{Q} 2, n=7), 4.3$ (Q3, $n=12)$, and 2.8 months $(\mathrm{Q} 4, n=3)$, and was not statistically different among the quartile groups $(p=0.098)$. Nine patients $(16 \%)$ had a $C_{\text {min }}$ below the threshold concentration of $490 \mu \mathrm{g} / \mathrm{L}$ at any time (range 196-467), of whom six patients (11\%) once and two patients (4\%) twice. One patient $(2 \%)$ had four $C_{\text {min }}$ values below $490 \mu \mathrm{g} / \mathrm{L}$. These patients did not differ in time to $\mathrm{MMR}_{12}$ from those with $C_{\min }$ above $490 \mu \mathrm{g} / \mathrm{L}$.

\section{Discussion}

This comprehensive observational study in CP-CML patients using nilotinib aimed to obtain insight into their adherence to treatment and its influence on drug exposure and treatment outcomes. The median adherence to nilotinib was high $(\geq$ $99 \%$ ) and adherence lower than $90 \%$ was rare. Nevertheless, after 12 months of treatment, about a third of the patients reported occasional nonadherence. In line with the high belief of patients in the necessity of taking nilotinib, forgetting to take a dose was more prevalent than intentionally adjusting or skipping doses. Although the intra-patient variability was high, nilotinib $\mathrm{C}_{\min }$ values were generally above the therapeutic target in $95 \%$ of patients. Patients reported a variety of side effects, of which fatigue was most frequent. The mean $C_{\min }$ was higher in patients who reported severe itching and fatigue.

Several studies assessing patients' adherence to nilotinib using objective measures reported generally lower rates of adherence [23-35]. However, various methodological issues (i.e., study design and setting, follow-up period, assessment measure) limit comparison across studies [37, 54, 55]. Most of the studies were retrospective using claims data or pharmacy refill data [23-32, 35]. The sample sizes of these studies were larger and its data gathered unobtrusively without patient involvement. In the present study, nonadherent patients may have been less willing to participate which may lead to an over-estimation of adherence. In addition, studies using claims data or pharmacy refill data may underestimate the level of adherence because dose reductions are generally not taking into account in time. As yet prospectively obtained data are limited to those of ten patients participating in the TAKE-IT study investigating adherence by means of MEMS in CP-

Table 5 Adherence, $C_{\min }$, and molecular response to nilotinib treatment

\begin{tabular}{|c|c|c|c|c|c|}
\hline \multicolumn{6}{|c|}{ Adherence and molecular response to nilotinib treatment } \\
\hline & \multicolumn{2}{|c|}{ Adherence using MEMS } & \multicolumn{3}{|c|}{ Adherence using pill count } \\
\hline & $n$ & Mean \pm SD & $p$ & Mean \pm SD & $p$ \\
\hline All patients & & & .683 & & .927 \\
\hline Optimal response & 15 & $95.0 \pm 8.7 \%$ & & $96.9 \pm 11.0 \%$ & \\
\hline Suboptimal response & 11 & $94.6 \pm 11.9 \%$ & & $99.0 \pm 2.6 \%$ & \\
\hline Subpopulation 1A/1B (1st line treatment) & & & .441 & & .444 \\
\hline Optimal response & 11 & $97.0 \pm 5.0 \%$ & & $97.3 \pm 9.9 \%$ & \\
\hline Suboptimal response & 5 & $93.9 \pm 13.1 \%$ & 6 & $100.7 \pm 1.2 \%$ & \\
\hline Subpopulation $2 \mathrm{~A} / 2 \mathrm{~B}$ ( $\geq 2$ nd line treatment) & & & .352 & & .731 \\
\hline Optimal response & 4 & $88.0 \pm 22.3 \%$ & 7 & $96.0 \pm 13.8 \%$ & \\
\hline Suboptimal response & 6 & $95.9 \pm 3.7 \%$ & 6 & $97.3 \pm 2.6 \%$ & \\
\hline \multicolumn{6}{|c|}{ Nilotinib $C_{\min }$ and molecular response to nilotinib treatment } \\
\hline & \multicolumn{4}{|c|}{ 1-year MMR rate according to nilotinib $c_{\min }$} & $p$ \\
\hline & Q1 & Q2 & Q3 & Q4 & Q1 vs. Q2-Q4 \\
\hline All patients & $56 \%(5 / 9)$ & $88 \%(7 / 8)$ & $75 \%(12 / 16$ & $30 \%(3 / 10)$ & .706 \\
\hline Subpopulation $1 \mathrm{~A} / 1 \mathrm{~B}$ (1st line treatment) & $71 \%(5 / 7)$ & $100 \%(5 / 5)$ & $73 \%(8 / 11)$ & $40 \%(2 / 5)$ & .999 \\
\hline Subpopulation $2 \mathrm{~A} / 2 \mathrm{~B}$ ( $\geq 2$ nd line treatment) & $0 \%(0 / 2)$ & $75 \%(2 / 3)$ & $80 \%(4 / 5)$ & $20 \%(1 / 5)$ & .467 \\
\hline
\end{tabular}

Abbreviations: $C_{\min }$, trough plasma concentration; $M E M S$, Medication Event Monitoring System; $S D$, standard deviation; $Q$, quartile

Optimal and suboptimal responses were defined as time to major molecular response $\leq 12$ months and $>12$ months, respectively. $C_{\min }$ quartiles were Q1 $(<635 \mu \mathrm{g} / \mathrm{L}), \mathrm{Q} 2-\mathrm{Q} 3(635-<1346 \mu \mathrm{g} / \mathrm{L}), \mathrm{Q} 4(\geq 1346 \mu \mathrm{g} / \mathrm{L})$ 
CML patients using imatinib, dasatinib, or nilotinib $[36,56]$. Although the median overall adherence $(97.5 \%)$ for all TKI was similar to that found in the present study, adherence was somewhat lower in patients treated with nilotinib as compared with imatinib and dasatinib.

In accordance with the findings of a recent review comparing MEMS with pill count and self-report [54], in the present study, there was poor agreement between adherence as assessed by these measures. In $81 \%$ of the studies reviewed, a significant difference between the rates obtained by applying each of these measures was found [54]. Clearly, each measure obtains its data differently and identifies different components of adherence. Since MEMS provides detailed, objective data on adherence, it is most often considered to be the gold standard [57]. However, the use of this system is known to influence adherence [57]. Moreover, as the MEMS solely records the opening of the container, evidence that (the full dose of) medication is actually ingested is not provided [57]. The pill count method is less interfering than the use of MEMS but fails to provide insight into adherence patterns [55, 58]. Likewise, it does not provide evidence that medication is actually taken. Subjective measures generally provide explanations for nonadherence; however, results can be biased by patients giving false information $[55,58]$. Therefore, a combination of objective and subjective measures is considered the best solution to assess medication adherence $[55,58]$.

Although the adherence over the full study period was high, occasional nonadherence measured with MARS-5 increased in the first year of nilotinib treatment to a third of the patients. This finding is consistent with the results of other studies [39, 59, 17]. Over time, patients become accustomed to living with a chronic disease and taking medication daily. Due to apparently successful treatment, patients increasingly participate in social and occupational activities. However, this often interferes with their daily routines which makes patients more easily to forget or skip a dose $[39,59,60,17]$. On the other hand, intentional nonadherence is mostly due to perceptual barriers (i.e., beliefs) [61, 62]. In the present study, forgetting to take nilotinib was found to be more prevalent than intentionally skipping or adjusting a dose and could be explained by the strong beliefs of patients in the necessity of taking nilotinib. The seriousness of the disease and clinical importance of TKI treatment are likely to reflect a patients' perceived need for treatment [63]. HCP should encourage CPCML patients using nilotinib to use practical aids (such as alarm devices and pill boxes) in order to avoid forgetting their medication as part of measures that prevent adherence to decline over time. In line with the results of a recently published worldwide patient survey by the CML Advocates Network [39], in the present, study female patients reported nonadherence more often than male patients.

A quarter of the patients did not consistently follow the recommendation to take nilotinib at least $1 \mathrm{~h}$ before or $2 \mathrm{~h}$ after a meal [53]. Food substantially increases nilotinib bioavailability [16, 64] which may cause adverse events [12]. Clearly, patients should be supported in correctly taking nilotinib in order to avoid potentially hazardous nilotinib concentrations. On the other hand, by applying a lower dose, the food-dependent bioavailability of nilotinib can be used to improve intake conditions [64]. As this simplified dosing regimen is likely to promote adherence and quality of life, its usefulness in daily practice should be further explored [64].

The prevalence rates of headache, nausea, rash, itching, and myalgia found in the present real-world study were essentially similar to those found in the ENESTnd trial [65]. Fatigue was reported by about one-fifth of the patients in this trial [65]. In contrast, in the present study, this debilitating side effect was reported by about three quarters of the patients. The lower prevalence of fatigue in the ENESTnd trial [65] might be explained by the propensity of HCP to underestimate symptomatic, subjective side effects [66,67]. Our findings are in line with those of other studies providing data on patientreported side effects [68-70]. Although nilotinib side effects are generally mild, they do adversely impact the patients' quality of life $[71,68,72]$. Considering the long duration of CML treatment and increased risk of treatment interruption, discontinuation, or switching due to side effects, it is important to actively inquire after (perceived) side effects and subsequently support patients in mitigating their effects [73]. Remarkably, the mean $C_{\min }$ of nilotinib was higher in patients reporting severe itching and fatigue. As yet higher nilotinib $C_{\min }$ have only been associated with the occurrence of allgrade elevations in total bilirubin and lipase levels and increases in QTc changes $[12,13]$. Therapeutic drug monitoring (TDM) may prevent the emergence of potentially hazardous nilotinib plasma concentrations. On the other hand, in certain patients with higher $C_{\min }$, the dose might be reduced on the basis of TDM without compromising treatment efficacy.

CML patients vary greatly in their responses to treatment. In the present study, $71 \%$ of the patients on first-line nilotinib treatment achieved a 1-year MMR rate. This is higher than the $55 \%$ rate reported in the 5-year update of the ENESTnd trial [65]. In this study of highly adherent patients, we could not identify whether a lack of adherence contributed to a lack of response. The same applied for nilotinib blood levels, which were generally above the minimum therapeutic target. Apparently, in this group of patients, the incapacity to achieve a MMR during 1 year of treatment seemed not related to nonadherence or inadequate nilotinib blood levels. However, the underpowering of the study due to the unavoidable heterogeneity of its study population precludes any definitive conclusions.

The present study has some strengths and limitations. A major strength is its prospective design that provides a unique and complete survey of nilotinib treatment in daily practice. A wide range of variables was longitudinally collected by means 
of questionnaires, blood sampling, adherence measures, and data retrieved from medical files and pharmacy records. To our knowledge, this is the first study in which these real-life nilotinib data have been evaluated together. Another strength is the assessment of medication adherence, which was prospectively implemented using both objective and subjective measures. Also, it includes a long follow-up of 12 months. Unfortunately, in the Netherlands, the number of patients treated with nilotinib is relatively small resulting in a poor initial accrual of newly diagnosed CP-CML patients. Consequently, the study protocol had to be amended to include both patients already treated with nilotinib treatment and those with prior TKI treatment. Selection bias may have occurred, as nonadherent patients may have been less willing to participate. In addition, patients willing to participate may be more attentive to treatment, resulting in optimal responses, adherence, and nilotinib blood levels in our group of patients. Caution should be used when generalizing the findings to other CML patients. The inability to collect adherence data at treatment onset in patients already on nilotinib treatment (subpopulations 1B/2B) may have biased the results of the adherence-outcome analyses as mean adherence values were used, whereas our analyses showed that self-reported nonadherence increased over time in subpopulation $1 \mathrm{~A}$. Another limitation is the amount of missing data. In order to minimize their influence on outcomes, we have decided to limit imputation to the exposure-outcome and exposurefactors analyses.

\section{Conclusion}

Although in most patients in the present study the extent of nonadherence to nilotinib appeared not to be clinically relevant with respect to achieving an optimal response, it is clear that a considerable number of patients experienced difficulties in adhering to the recommended twice daily fasted dosing regimen. Current clinical practice may be improved by fostering the intention to adhere and by encouraging patients to use practical aids that are particularly relevant to avoid the occurrence of unintentional nonadherence. Since adherence decreases by treatment duration, interventions aimed at longterm correct use of nilotinib are also relevant. Furthermore, HCP should inquire after (perceived) side effects and take adequate measures to mitigate these effects, in particular the occurrence of fatigue. TDM whether or not in combination with dose reduction may be considered in order to avoid unnecessary high blood levels causing severe side effects.

Acknowledgments We thank the patients and all study personnel in the different centers for their efforts. We thank Jan Jacob Beckeringh for editorial assistance with this manuscript.
Authors' contribution $\mathrm{CB}, \mathrm{LT}, \mathrm{JJ}, \mathrm{ES}$, and JH designed the study. CB, JJ, $\mathrm{PW}, \mathrm{NB}$, and WS were involved in patient recruitment. $\mathrm{CB}$ was responsible for acquisition of the data. CB, LT, JJ, PW, NB, IB, JW, NH, and JH were involved in data analysis; $\mathrm{CB}$ performed data analysis. $\mathrm{CB}$ drafted the manuscript and LT, JJ, PW, NB, WS, IB, JW, ES, NH, and JH critically revised the manuscript. All authors gave the final approval of the manuscript to be published. ES was the principal investigator.

Funding information This study was funded by Novartis (grant number CAMN107ENL04T). The authors are responsible for the content of the article.

\section{Compliance with ethical standards}

The study was approved by the Medical Ethics review board of the Amsterdam University Medical Centers (location VUmc, Amsterdam)(2013.035), as well as the ethical boards of each participating center (Albert Schweitzer Hospital Dordrecht, Medical Spectrum Twente Enschede, University Medical Centre Groningen, University Medical Centre Utrecht, and Radboudumc Nijmegen). All procedures performed were in accordance with the ethical standards of the Medical Ethics review board and with the 1964 Helsinki declaration and its later amendments or comparable ethical standards. Informed consent was obtained from all individual participants included in the study.

Conflict of interest J.J.W.M. Janssen is an advisory board member for Abbvie, Incyte, Jazz Pharmaceuticals, and Pfizer, and has received research support funding from Novartis and Bristol Myers Squibb and speaker's fees from Incyte and Pfizer. P.E. Westerweel has been an advisory board member for Novartis and has received research support funding from Novartis. N.M.A. Blijlevens has received funding of Novartis, Bristol Myers Squibb, Pfizer, and Incyte for web-based platform CMyLife. W.M. Smit has been an advisory board member for Roche and Novartis. The other authors declare no conflict of interest.

Open Access This article is licensed under a Creative Commons Attribution 4.0 International License, which permits use, sharing, adaptation, distribution and reproduction in any medium or format, as long as you give appropriate credit to the original author(s) and the source, provide a link to the Creative Commons licence, and indicate if changes were made. The images or other third party material in this article are included in the article's Creative Commons licence, unless indicated otherwise in a credit line to the material. If material is not included in the article's Creative Commons licence and your intended use is not permitted by statutory regulation or exceeds the permitted use, you will need to obtain permission directly from the copyright holder. To view a copy of this licence, visit http://creativecommons.org/licenses/by/4.0/.

\section{References}

1. Hochhaus A, Saussele S, Rosti G, Mahon FX, Janssen JJ, HjorthHansen H, Richter J, Buske C, Committee EG (2017) Chronic myeloid leukaemia: ESMO Clinical Practice Guidelines for diagnosis, treatment and follow-up. Ann Oncol 28:iv41-iv51. https:// doi.org/10.1093/annonc/mdx219

2. Gambacorti-Passerini C, Antolini L, Mahon FX, Guilhot F, Deininger M, Fava C, Nagler A, Della Casa CM, Morra E, Abruzzese E, D'Emilio A, Stagno F, le Coutre P, HurtadoMonroy R, Santini V, Martino B, Pane F, Piccin A, Giraldo P, Assouline S, Durosinmi MA, Leeksma O, Pogliani EM, Puttini M, Jang E, Reiffers J, Piazza R, Valsecchi MG, Kim DW (2011) Multicenter independent assessment of outcomes in chronic 
myeloid leukemia patients treated with imatinib. J Natl Cancer Inst 103:553-561. https://doi.org/10.1093/jnci/djr060

3. Saussele S, Krauss MP, Hehlmann R, Lauseker M, Proetel U, Kalmanti L, Hanfstein B, Fabarius A, Kraemer D, Berdel WE, Bentz M, Staib P, de Wit M, Wernli M, Zettl F, Hebart HF, Hahn M, Heymanns J, Schmidt-Wolf I, Schmitz N, Eckart MJ, Gassmann W, Bartholomaus A, Pezzutto A, Leibundgut EO et al (2015) Impact of comorbidities on overall survival in patients with chronic myeloid leukemia: results of the randomized CML study IV. Blood 126:42-49. https://doi.org/10.1182/blood-2015-01-617993

4. Breccia M, Colafigli G, Molica M, Alimena G (2016) Adverse events associated with tyrosine kinase inhibitors for the treatment of chronic myeloid leukemia. Expert Opin Drug Saf 15:525-533. https://doi.org/10.1517/14740338.2016.1145654

5. Douxfils J, Haguet H, Mullier F, Chatelain C, Graux C, Dogne JM (2016) Association between BCR-ABL tyrosine kinase inhibitors for chronic myeloid leukemia and cardiovascular events, major molecular response, and overall survival: a systematic review and meta-analysis. JAMA Oncol 2:625-632. https://doi.org/10.1001/ jamaoncol.2015.5932

6. Damrongwatanasuk R, Fradley MG (2017) Cardiovascular complications of targeted therapies for chronic myeloid leukemia. Curr Treat Options Cardiovasc Med 19:24. https://doi.org/10.1007/ s11936-017-0524-8

7. Hughes TP, Ross DM (2016) Moving treatment-free remission into mainstream clinical practice in CML. Blood 128:17-23. https://doi. org/10.1182/blood-2016-01-694265

8. Hughes T, Saglio G, Branford S, Soverini S, Kim DW, Muller MC, Martinelli G, Cortes J, Beppu L, Gottardi E, Kim D, Erben P, Shou Y, Haque A, Gallagher N, Radich J, Hochhaus A (2009) Impact of baseline BCR-ABL mutations on response to nilotinib in patients with chronic myeloid leukemia in chronic phase. J Clin Oncol 27: 4204-4210. https://doi.org/10.1200/JCO.2009.21.8230

9. Patel AB, O'Hare T, Deininger MW (2017) Mechanisms of resistance to ABL kinase inhibition in chronic myeloid leukemia and the development of next generation ABL kinase inhibitors. Hematol Oncol Clin North Am 31:589-612. https://doi.org/10.1016/j.hoc. 2017.04.007

10. Miura M (2015) Therapeutic drug monitoring of imatinib, nilotinib, and dasatinib for patients with chronic myeloid leukemia. Biol Pharm Bull 38:645-654. https://doi.org/10.1248/bpb.b15-00103

11. Verheijen RB, Yu H, Schellens JHM, Beijnen JH, Steeghs N, Huitema ADR (2017) Practical recommendations for therapeutic drug monitoring of kinase inhibitors in oncology. Clin Pharmacol Ther 102:765-776. https://doi.org/10.1002/cpt.787

12. Larson RA, Yin OQ, Hochhaus A, Saglio G, Clark RE, Nakamae H, Gallagher NJ, Demirhan E, Hughes TP, Kantarjian HM, le Coutre PD (2012) Population pharmacokinetic and exposure-response analysis of nilotinib in patients with newly diagnosed $\mathrm{Ph}+$ chronic myeloid leukemia in chronic phase. Eur J Clin Pharmacol 68:723-733. https://doi.org/10.1007/s00228-011-1200-7

13. Giles FJ, Yin OQ, Sallas WM, le Coutre PD, Woodman RC, Ottmann OG, Baccarani M, Kantarjian HM (2013) Nilotinib population pharmacokinetics and exposure-response analysis in patients with imatinib-resistant or -intolerant chronic myeloid leukemia. Eur J Clin Pharmacol 69:813-823. https://doi.org/10.1007/ s00228-012-1385-4

14. Picard S, Titier K, Etienne G, Teilhet E, Ducint D, Bernard MA, Lassalle R, Marit G, Reiffers J, Begaud B, Moore N, Molimard M, Mahon FX (2007) Trough imatinib plasma levels are associated with both cytogenetic and molecular responses to standard-dose imatinib in chronic myeloid leukemia. Blood 109:3496-3499. https://doi.org/10.1182/blood-2006-07-036012

15. Guilhot F, Hughes TP, Cortes J, Druker BJ, Baccarani M, Gathmann I, Hayes M, Granvil C, Wang Y (2012) Plasma exposure of imatinib and its correlation with clinical response in the
Tyrosine Kinase Inhibitor Optimization and Selectivity Trial. Haematologica 97:731-738. https://doi.org/10.3324/haematol. 2011.045666

16. Tanaka C, Yin OQ, Sethuraman V, Smith T, Wang X, Grouss K, Kantarjian H, Giles F, Ottmann OG, Galitz L, Schran H (2010) Clinical pharmacokinetics of the BCR-ABL tyrosine kinase inhibitor nilotinib. Clin Pharmacol Ther 87:197-203. https://doi.org/10. 1038/clpt.2009.208

17. Noens L, van Lierde MA, De Bock R, Verhoef G, Zachee P, Berneman Z, Martiat P, Mineur P, Van Eygen K, MacDonald K, De Geest S, Albrecht T, Abraham I (2009) Prevalence, determinants, and outcomes of nonadherence to imatinib therapy in patients with chronic myeloid leukemia: the ADAGIO study. Blood 113:5401-5411. https://doi.org/10.1182/blood-2008-12-196543

18. Marin D, Bazeos A, Mahon F, Eliasson L, Milojkovic D, Bua M, Apperley J, Szydlo R, Desai R, Kozlowski K, Paliompeis C, Latham V, Foroni L, Molimard M, Reid A, Rezvani K, de Lavallade H, Guallar C, Goldman J, Khorashad J (2010) Adherence is the critical factor for achieving molecular responses in patients with chronic myeloid leukemia who achieve complete cytogenetic responses on imatinib. J Clin Oncol 28:2381-2388. https://doi.org/10.1200/JCO.2009.26.3087

19. Ganesan P, Sagar TG, Dubashi B, Rajendranath R, Kannan K, Cyriac S, Nandennavar M (2011) Nonadherence to imatinib adversely affects event free survival in chronic phase chronic myeloid leukemia. Am J Hematol 86:471-474. https://doi.org/10.1002/ajh. 22019

20. Ibrahim AR, Eliasson L, Apperley JF, Milojkovic D, Bua M, Szydlo R, Mahon FX, Kozlowski K, Paliompeis C, Foroni L, Khorashad JS, Bazeos A, Molimard M, Reid A, Rezvani K, Gerrard G, Goldman J, Marin D (2011) Poor adherence is the main reason for loss of CCyR and imatinib failure for chronic myeloid leukemia patients on long-term therapy. Blood 117:3733-3736. https://doi.org/10.1182/blood-2010-10-309807

21. Al-Dewik NI, Morsi HM, Samara MM, Ghasoub RS, Gnanam CC, Bhaskaran SK, Nashwan AJ, Al-Jurf RM, Ismail MA, AlSharshani MM, AlSayab AA, Ben-Omran TI, Khatib RB, Yassin MA (2016) Is adherence to imatinib mesylate treatment among patients with chronic myeloid leukemia associated with better clinical outcomes in Qatar? Clin Med Insights Oncol 10:95-104. https://doi.org/10. 4137/CMO.S32822

22. Santoleri F, Lasala R, Ranucci E, La Barba G, Di Lorenzo R, Vetro A, Di Bartolomeo P, Costantini A (2016) Medication adherence to tyrosine kinase inhibitors: 2-year analysis of medication adherence to imatinib treatment for chronic myeloid leukemia and correlation with the depth of molecular response. Acta Haematol 136:45-51. https://doi.org/10.1159/000444626

23. Wu EQ, Guerin A, Yu AP, Bollu VK, Guo A, Griffin JD (2010) Retrospective real-world comparison of medical visits, costs, and adherence between nilotinib and dasatinib in chronic myeloid leukemia. Curr Med Res Opin 26:2861-2869. https://doi.org/10.1185/ 03007995.2010.533648

24. Guerin A, Chen L, Wu EQ, Ponce de Leon D, Griffin JD (2012) A retrospective analysis of therapy adherence in imatinib resistant or intolerant patients with chronic myeloid leukemia receiving nilotinib or dasatinib in a real-world setting. Curr Med Res Opin 28:1155-1162. https://doi.org/10.1185/03007995.2012.705264

25. Yood MU, Oliveria SA, Cziraky M, Hirji I, Hamdan M, Davis C (2012) Adherence to treatment with second-line therapies, dasatinib and nilotinib, in patients with chronic myeloid leukemia. Curr Med Res Opin 28:213-219. https://doi.org/10.1185/03007995.2011. 649849

26. Santoleri F, Sorice P, Lasala R, Rizzo RC, Costantini A (2013) Patient adherence and persistence with imatinib, nilotinib, dasatinib in clinical practice. PLoS One 8:e56813. https://doi.org/10.1371/ journal.pone. 0056813 
27. Trivedi D, Landsman-Blumberg P, Darkow T, Smith D, McMorrow D, Mullins CD (2014) Adherence and persistence among chronic myeloid leukemia patients during second-line tyrosine kinase inhibitor treatment. J Manag Care Spec Pharm 20: 1006-1015. https://doi.org/10.18553/jmcp.2014.20.10.1006

28. Anderson KR, Chambers CR, Lam N, Yau PS, Cusano F, Savoie ML, Sheikh N (2015) Medication adherence among adults prescribed imatinib, dasatinib, or nilotinib for the treatment of chronic myeloid leukemia. J Oncol Pharm Pract 21:19-25. https://doi.org/ $10.1177 / 1078155213520261$

29. Winn AN, Keating NL, Dusetzina SB (2016) Factors associated with tyrosine kinase inhibitor initiation and adherence among medicare beneficiaries with chronic myeloid leukemia. J Clin Oncol 34: 4323-4328. https://doi.org/10.1200/JCO.2016.67.4184

30. Haque R, Shi J, Chung J, Xu X, Avila C, Campbell C, Ahmed SA, Chen L, Schottinger JE (2017) Medication adherence, molecular monitoring, and clinical outcomes in patients with chronic myelogenous leukemia in a large HMO. J Am Pharm Assoc 57(2003):303310 e302. https://doi.org/10.1016/j.japh.2017.01.004

31. Ward MA, Fang G, Richards KL, Walko CM, Earnshaw SR, Happe LE, Blalock SJ (2015) Comparative evaluation of patients newly initiating first-generation versus second-generation tyrosine kinase inhibitors for chronic myeloid leukemia and medication adherence, health services utilization, and healthcare costs. Curr Med Res Opin 31:289-297. https://doi.org/10.1185/03007995.2014. 991440

32. Latremouille-Viau D, Guerin A, Gagnon-Sanschagrin P, Dea K, Cohen BG, Joseph GJ (2017) Health care resource utilization and costs in patients with chronic myeloid leukemia with better adherence to tyrosine kinase inhibitors and increased molecular monitoring frequency. J Manag Care Spec Pharm 23:214-224. https://doi. org/10.18553/jmcp.2017.23.2.214

33. Timmers L, Boons CC, Kropff F, van de Ven PM, Swart EL, Smit EF, Zweegman S, Kroep JR, Timmer-Bonte JN, Boven E, Hugtenburg JG (2014) Adherence and patients' experiences with the use of oral anticancer agents. Acta Oncol 53:259-267. https:// doi.org/10.3109/0284186X.2013.844353

34. Santoleri F, Lasala R, Logreco A, Ranucci E, Costantini A (2019) Using a treatment diary to improve the medication adherence in patients with chronic myeloid leukaemia. J Oncol Pharm Pract 25: 1035-1041. https://doi.org/10.1177/1078155218759184

35. de Almeida MH, Pagnano KB, Vigorito AC, Lorand-Metze I, de Souza CA (2013) Adherence to tyrosine kinase inhibitor therapy for chronic myeloid leukemia: a Brazilian single-center cohort. Acta Haematol 130:16-22. https://doi.org/10.1159/000345722

36. Leader A, Gafter-Gvili A, Benyamini N, Dreyer J, Calvarysky B, Amitai A, Yarchovsky-Dolberg O, Sharf G, Tousset E, Caspi O, Ellis M, Levi I, Raanani P, De Geest S (2018) Identifying tyrosine kinase inhibitor nonadherence in chronic myeloid leukemia: subanalysis of TAKE-IT pilot study. Clin Lymphoma Myeloma Leuk 18:e351-e362. https://doi.org/10.1016/j.clml.2018.06.007

37. Noens L, Hensen M, Kucmin-Bemelmans I, Lofgren C, Gilloteau I, Vrijens B (2014) Measurement of adherence to BCR-ABL inhibitor therapy in chronic myeloid leukemia: current situation and future challenges. Haematologica 99:437-447. https://doi.org/10.3324/ haematol.2012.082511

38. Hall AE, Paul C, Bryant J, Lynagh MC, Rowlings P, Enjeti A, Small H (2016) To adhere or not to adhere: rates and reasons of medication adherence in hematological cancer patients. Crit Rev Oncol Hematol 97:247-262. https://doi.org/10.1016/j.critrevonc. 2015.08.025

39. Geissler J, Sharf G, Bombaci F, Daban M, De Jong J, Gavin T, Pelouchova J, Dziwinski E, Hasford J, Hoffmann VS (2017) Factors influencing adherence in CML and ways to improvement: results of a patient-driven survey of 2546 patients in 63 countries. J
Cancer Res Clin Oncol 143:1167-1176. https://doi.org/10.1007/ s00432-017-2372-z

40. Kavookjian J, Wittayanukorn S (2015) Interventions for adherence with oral chemotherapy in hematological malignancies: a systematic review. Res Soc Adm Pharm 11:303-314. https://doi.org/10. 1016/j.sapharm.2014.08.006

41. Boons CC, Swart EL, Timmers L, van de Ven PM, Janssen JJ, Hugtenburg JG (2014) Study protocol of the RAND-study: a multicenter, prospective cohort study investigating response and adherence to nilotinib treatment in chronic myeloid leukemia. BMC Cancer 14:247. https://doi.org/10.1186/1471-2407-14-247

42. Janssen JJ, Cornelissen JJ, Posthuma EF, Falkenburg JHF, Biemond BJ, Bos GMJ, Petersen EJ, Schattenberg AV (2014) Guidelines for the treatment of chronic myeloid leukemia in the year 2014 (Richtlijnen voor de behandeling van chronische myeloïde leukemie anno 2014). Ned Tijdschr Hematol 11:185-198

43. Vrijens B, De Geest S, Hughes DA, Przemyslaw K, Demonceau J, Ruppar T, Dobbels F, Fargher E, Morrison V, Lewek P, Matyjaszczyk M, Mshelia C, Clyne W, Aronson JK, Urquhart J (2012) A new taxonomy for describing and defining adherence to medications. Br J Clin Pharmacol 73:691-705. https://doi.org/10. $1111 / \mathrm{j} .1365-2125.2012 .04167$

44. Horne R (2017) The Medication Adherence Report Scale (MARS): a new measurement tool for eliciting patients' report non-adherence [Working paper]. University of Brighton, Mayfield House, United Kingdom

45. Cohen JL, Mann DM, Wisnivesky JP, Home R, Leventhal H, Musumeci-Szabo TJ, Halm EA (2009) Assessing the validity of self-reported medication adherence among inner-city asthmatic adults: the Medication Adherence Report Scale for Asthma. Ann Allergy Asthma Immunol 103:325-331. https://doi.org/10.1016/ S1081-1206(10)60532-7

46. Mora PA, Berkowitz A, Contrada RJ, Wisnivesky J, Horne R, Leventhal H, Halm EA (2011) Factor structure and longitudinal invariance of the Medical Adherence Report Scale-Asthma. Psychol Health 26:713-727. https://doi.org/10.1080/08870446. 2010.490585

47. Boons CC, Chahbouni A, Schimmel AM, Wilhelm AJ, den Hartog YM, Janssen JJ, Hendrikse NH, Hugtenburg JG, Swart EL (2017) Dried blood spot sampling of nilotinib in patients with chronic myeloid leukaemia: a comparison with venous blood sampling. J Pharm Pharmacol 69:1265-1274. https://doi.org/10.1111/jphp. 12757

48. Boons CC, Timmers L, Janssen JJ, Swart EL, Hugtenburg JG, Hendrikse NH (2019) Feasibility of and patients' perspective on nilotinib dried blood spot self-sampling. Eur J Clin Pharmacol 75: 825-829. https://doi.org/10.1007/s00228-019-02640-1

49. Hurst NP, Ruta DA, Kind P (1998) Comparison of the MOS short form-12 (SF12) health status questionnaire with the SF36 in patients with rheumatoid arthritis. Br J Rheumatol 37:862-869. https://doi.org/10.1093/rheumatology/37.8.862

50. Horne R, Weinman J, Hankins M (1999) The beliefs about medicines questionnaire: the development and evaluation of a new method for assessing the cognitive representation of medication. Psychol Health 14:1-24. https://doi.org/10.1080/08870449908407311

51. Horne R, Hankins M, Jenkins R (2001) The Satisfaction with Information about Medicines Scale (SIMS): a new measurement tool for audit and research. Qual Health Care 10:135-140. https:// doi.org/10.1136/qhc.0100135

52. Broadbent E, Petrie KJ, Main J, Weinman J (2006) The brief illness perception questionnaire. J Psychosom Res 60:631-637. https:// doi.org/10.1016/j.jpsychores.2005.10.020

53. European Public Assessment Report Tasigna Product Information. (2019) European Medicines Agency. http://www.ema.europa.eu.

54. El Alili M, Vrijens B, Demonceau J, Evers SM, Hiligsmann M (2016) A scoping review of studies comparing the medication event 
monitoring system (MEMS) with alternative methods for measuring medication adherence. Br J Clin Pharmacol 82:268-279. https:// doi.org/10.1111/bcp.12942

55. Lam WY, Fresco P (2015) Medication adherence measures: an overview. Biomed Res Int 2015:217047-217012. https://oi.org/ $10.1155 / 2015 / 217047$

56. Leader A, Benyamini N, Gafter-Gvili A, Dreyer J, Calvarysky B, Amitai A, Yarchovsky-Dolberg O, Sharf G, Tousset E, Caspi O, Ellis M, Levi I, De Geest S, Raanani P (2018) Effect of adherenceenhancing interventions on adherence to tyrosine kinase inhibitor treatment in chronic myeloid leukemia (TAKE-IT): a quasiexperimental pre-post intervention multicenter pilot study. Clin Lymphoma Myeloma Leuk 18:e449-e461. https://doi.org/10. 1016/j.clml.2018.06.026

57. Hartman L, Lems WF, Boers M (2019) Outcome measures for adherence data from a medication event monitoring system: a literature review. J Clin Pharm Ther 44:1-5. https://doi.org/10.1111/ jcpt. 12757

58. Forbes CA, Deshpande S, Sorio-Vilela F, Kutikova L, Duffy S, Gouni-Berthold I, Hagstrom E (2018) A systematic literature review comparing methods for the measurement of patient persistence and adherence. Curr Med Res Opin 34:1613-1625. https:// doi.org/10.1080/03007995.2018.1477747

59. Halpern R, Barghout V, Zarotsky V, Williams DE (2009) Costs and utilization associated with imatinib adherence in patients with chronic myeloid leukemia or gastrointestinal stromal tumors. J Clin Outcomes Manag 16:215-223

60. Boons CC, Harbers L, Timmers L, de Jong J, Swart EL, Hendrikse $\mathrm{NH}$, Janssen JJ, Hugtenburg JG (2018) Needs for information and reasons for (non)adherence in chronic myeloid leukaemia: be aware of social activities disturbing daily routines. Eur J Haematol 101: 643-653. https://doi.org/10.1111/ejh.13155

61. Wroe AL (2002) Intentional and unintentional nonadherence: a study of decision making. J Behav Med 25:355-372. https://doi. org/10.1023/A:1015866415552

62. Kane SV, Robinson A (2010) Review article: understanding adherence to medication in ulcerative colitis - innovative thinking and evolving concepts. Aliment Pharmacol Ther 32:1051-1058. https:// doi.org/10.1111/j.1365-2036.2010.04445.x

63. Horne R, Chapman SC, Parham R, Freemantle N, Forbes A, Cooper V (2013) Understanding patients' adherence-related beliefs about medicines prescribed for long-term conditions: a metaanalytic review of the Necessity-Concerns Framework. PLoS One 8:e80633. https://doi.org/10.1371/journal.pone.0080633

64. Boons CC, Den Hartog YM, Janssen JJWM, Zandvliet AS, Vos RM, Swart EL, Hendrikse NH, Hugtenburg JG (2018) Food-effect study of nilotinib in chronic myeloid leukemia (NiFo study): enabling dose reduction and relief of treatment burden. Blood 132: 1732. https://doi.org/10.1182/blood-2018-99-118149

65. Hochhaus A, Saglio G, Hughes TP, Larson RA, Kim DW, Issaragrisil S, le Coutre PD, Etienne G, Dorlhiac-Llacer PE, Clark RE, Flinn IW, Nakamae H, Donohue B, Deng W, Dalal D, Menssen HD, Kantarjian HM (2016) Long-term benefits and risks of frontline nilotinib vs imatinib for chronic myeloid leukemia in chronic phase: 5-year update of the randomized ENESTnd trial. Leukemia 30:1044-1054. https://doi.org/10.1038/leu.2016.5
66. Basch E, Iasonos A, McDonough T, Barz A, Culkin A, Kris MG, Scher HI, Schrag D (2006) Patient versus clinician symptom reporting using the National Cancer Institute Common Terminology Criteria for Adverse Events: results of a questionnaire-based study. Lancet Oncol 7:903-909. https://doi. org/10.1016/S1470-2045(06)70910-X

67. Efficace F, Rosti G, Aaronson N, Cottone F, Angelucci E, Molica S, Vignetti M, Mandelli F, Baccarani M (2014) Patient- versus physician-reporting of symptoms and health status in chronic myeloid leukemia. Haematologica 99:788-793. https://doi.org/10.3324/ haematol.2013.093724

68. Zulbaran-Rojas A, Lin HK, Shi Q, Williams LA, George B, GarciaManero G, Jabbour E, O'Brien S, Ravandi F, Wierda W, Estrov Z, Borthakur G, Kadia T, Cleeland C, Cortes JE, Kantarjian H (2018) A prospective analysis of symptom burden for patients with chronic myeloid leukemia in chronic phase treated with frontline secondand third-generation tyrosine kinase inhibitors. Cancer Med 7: 5457-5469. https://doi.org/10.1002/cam4.1808

69. Efficace F, Baccarani M, Breccia M, Alimena G, Rosti G, Cottone F, Deliliers GL, Barate C, Rossi AR, Fioritoni G, Luciano L, Turri D, Martino B, Di Raimondo F, Dabusti M, Bergamaschi M, Leoni P, Simula MP, Levato L, Ulisciani S, Veneri D, Sica S, Rambaldi A, Vignetti M, Mandelli F et al (2011) Health-related quality of life in chronic myeloid leukemia patients receiving long-term therapy with imatinib compared with the general population. Blood 118: 4554-4560. https://doi.org/10.1182/blood-2011-04-347575

70. Williams LA, Garcia Gonzalez AG, Ault P, Mendoza TR, Sailors ML, Williams JL, Huang F, Nazha A, Kantarjian HM, Cleeland CS, Cortes JE (2013) Measuring the symptom burden associated with the treatment of chronic myeloid leukemia. Blood 122:641-647. https://doi.org/10.1182/blood-2013-01-477687

71. Efficace F, Baccarani M, Breccia M, Cottone F, Alimena G, Deliliers GL, Barate C, Specchia G, Di Lorenzo R, Luciano L, Turri D, Martino B, Stagno F, Dabusti M, Bergamaschi M, Leoni P, Simula MP, Levato L, Fava C, Veneri D, Sica S, Rambaldi A, Rosti G, Vignetti M, Mandelli F (2013) Chronic fatigue is the most important factor limiting health-related quality of life of chronic myeloid leukemia patients treated with imatinib. Leukemia 27 : 1511-1519. https://doi.org/10.1038/leu.2013.51

72. Guerin A, Chen L, Ionescu-Ittu R, Marynchenko M, Nitulescu R, Hiscock R, Keir C, Wu EQ (2014) Impact of low-grade adverse events on health-related quality of life in adult patients receiving imatinib or nilotinib for newly diagnosed Philadelphia chromosome positive chronic myelogenous leukemia in chronic phase. Curr Med Res Opin 30:2317-2328. https://doi.org/10.1185/03007995.2014. 944973

73. Boons CC, Tromp VN, Neppelenbroek NJ, Timmers L, van Schoor NM, Swart EL, Hendrikse NH, Janssen JJ, Hugtenburg JG (2019) Satisfaction with information on nilotinib treatment in chronic myeloid leukemia patients. Acta Oncol 58:891-896. https://doi.org/10. 1080/0284186X.2019.1585944

Publisher's note Springer Nature remains neutral with regard to jurisdictional claims in published maps and institutional affiliations. 